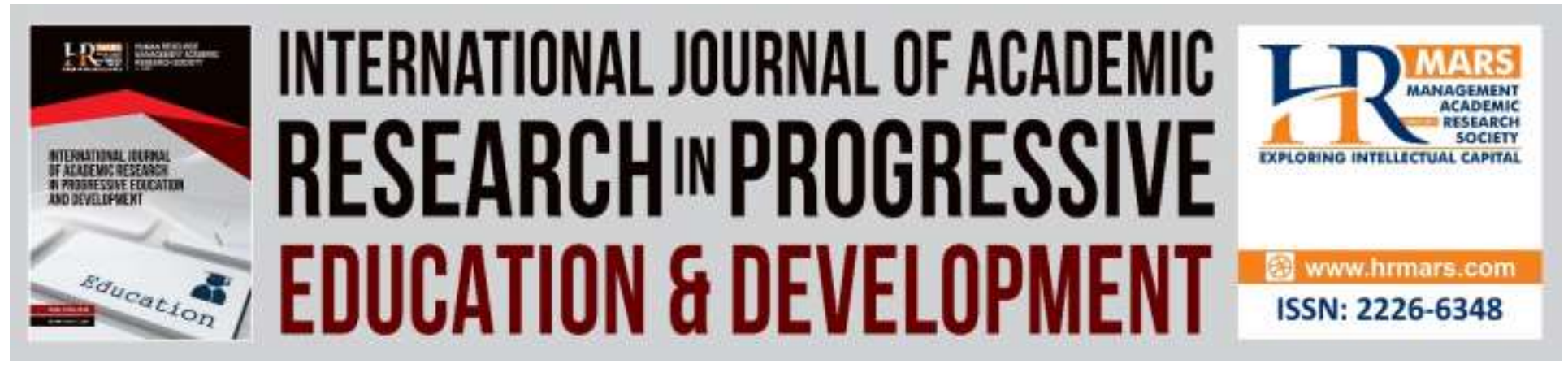

\title{
Improving Executive Functioning Skills in Children with Autism through Cognitive Training Program
}

Norfishah Mat Rabi, Monica Lau Jit May, Ng Meng Lek

To Link this Article: http://dx.doi.org/10.6007/IJARPED/v8-i3/6424

DOI: $10.6007 /$ IJARPED/v8-i3/6424

Received: 08 Aug 2019, Revised: 23 August 2019, Accepted: 05 September 2019

Published Online: 08 September, 2019

In-Text Citation: (Rabi, May, \& Lek, 2019)

To Cite this Article: Rabi, N. M., May, M. L. J., \& Lek, N. M. (2019). Improving Executive Functioning Skills in Children with Autism through Cognitive Training Program. International Journal of Academic Research in Progressive Education and Development, 8(3), 303-315.

Copyright: (C) 2019 The Author(s)

Published by Human Resource Management Academic Research Society (www.hrmars.com)

This article is published under the Creative Commons Attribution (CC BY 4.0) license. Anyone may reproduce, distribute, translate and create derivative works of this article (for both commercial and non-commercial purposes), subject to full attribution to the original publication and authors. The full terms of this license may be seen at: http://creativecommons.org/licences/by/4.0/legalcode

Vol. 8(3) 2019, Pg. 303 - 315

Full Terms \& Conditions of access and use can be found at http://hrmars.com/index.php/pages/detail/publication-ethics 


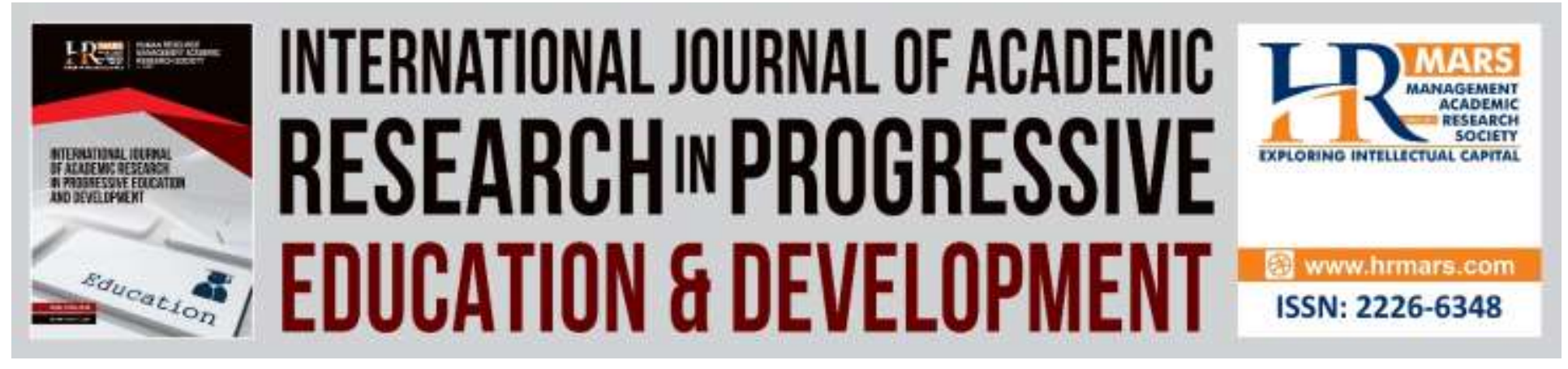

\title{
Improving Executive Functioning Skills in Children with Autism through Cognitive Training Program
}

\author{
Norfishah Mat Rabi ${ }^{1}$, Monica Lau Jit May², Ng Meng Lek ${ }^{3}$ \\ ${ }^{1}$ Faculty of Human Development, Universiti Pendidikan Sultan Idris, \\ Malaysia, ${ }^{2,3}$ MyNeuroLAT Sdn Bhd, Malaysia
}

\begin{abstract}
Autistic spectrum disorders are disorders that affect many aspects of thinking and learning. Specific intervention program should be provided for autistic to overcome the problem due to weaknesses in cognitive process. This study was conducted to investigate the effects of cognitive training in improving executive functioning skills among children with autism. The present study focused on skills in attention, working memory, transitioning, emotional regulation, abstract planning, impulse control, flexibility, and problem solving skills. This case study was conducted at National Autistic Society of Malaysia involving 10 children, age range between four to 12 years old. This study used the Cognitive Training Program which was designed for the purpose to train cognitive skills in children with autism. The data collection period were four months. Data collection methods used were observation, interviews and document analysis. The observation was conducted five times during the training session. Two sets of interview questions were designed and used in four interview sessions. The findings showed that this training were successfully improved executive functioning skills among participants but it depends on their ability to response to the training. Overall findings showed that participants were good in executive functions training. As a conclusion, cognitive training program is necessarily provided to help autistic children expand executive functioning skills effectively. Research implications indicate that cognitive training program should be promoted and expand to parents, teachers, caretaker and anyone who are engage with autistic children as an alternative intervention to be practiced systematically.
\end{abstract}

Keywords: Children with Autism, Cognitive Training, Executive Functioning Skills

\section{Introduction}

Autism spectrum conditions are a set of common, lifelong neurodevelopmental conditions that involve substantial heterogeneity at numerous levels, including etiology, neurobiology, cognition, and especially behavior (Pellicano, 2012). A very common characteristic of children with autism are easily distracted although they may display excellent concentration on their specific interest. They may not be able to give attention and stay focus if they are disturbed by background noise, lights or movement of other children. Children with autism find hardly to filter 
out this background noise and sensory information. A child with autism can have difficulty in understanding what they need to focus on, unaware of the big picture but preferred in concentrating instead on small, irrelevant details. Children with autism tend to have obsessive interests that can intrude on their thoughts. Many children with autistic spectrum disorders have relative strengths that can be used to boost their learning process. However, each autistic children shows a various characteristic differently and intervention should be provided depends on their needs. Treatment efforts are generally individualized, and can include behavioral therapy, and the teaching of coping skills. Medications may be used to try to help improve symptoms but evidence to support the use of medications, however, is not very strong (Accordino, Kidd, Politte, Henry, \& McDougle, (2016). Intervention can be provided as an alternative treatment for autism instead of medication.

There is a need for research on the development of more important areas of outcome in cognition, including the acquisition and generalization of problem-solving and other cognitive skills in natural contexts whether in the classroom or in the home environment. This study was carried out to develop cognitive skills through computerized cognitive training program. Children with autism need to improve executive functioning skills as a part of cognitive process. Thinking skills are the mental activities, used to process information, make decisions, make connections, and create new ideas. Given the essential role of executive function in children's successful development, numerous training programs have been developed to improve children's executive functioning skills.

\section{Literature Review}

According to the World Health Organization (WHO), Autism Spectrum Disorders (ASD) refers to a range of conditions characterized by varying degrees of impaired social behavior, communication and language, and a narrow range of interests and activities that are both unique to the individual and carried out repetitively. The new diagnosis encompasses previous diagnoses of autistic disorder, Asperger syndrome, childhood disintegrative disorder, and PDD-NOS. Compared with the DSM-IV diagnosis of autistic disorder, the DSM-5 diagnosis of ASD no longer includes communication as a separate criterion, and has merged social interaction and communication into one category (Kulage, Smaldone \& Cohn, 2014). Autism, Asperger syndrome, and PDD-NOS are sometimes called the autistic disorders instead of ASD (Freitag, 2007). Such clinical disorders include attention-deficit hyperactivity disorder (ADHD), obsessive-compulsive disorder, Tourette's syndrome, phenylketonuria, and schizophrenia (Hill, 2004). Individuals on the spectrum often present with problems with social communication and interaction; interests or activities (American Psychiatric Association, 2013) and restricted, repetitive patterns of behavior (Richler, Huerta, Bishop, \& Lord, 2010). Long term issues may include difficulties in performing daily tasks, creating and keeping relationships, and maintaining a job (Comer, 2016).

Some of the characteristic of autism are avoiding eye contact, preferring to be alone rather than engage with others, difficulty in understanding other people's feelings, exhibit delayed language development or nonverbal, echolalia (repeats words or phrases over and over), easily get upset by small changes in routine and surroundings, possesses highly restrictive interests, repetitive behaviors (such as spinning, rocking or flapping), and shows unusual or intense reactions to smells, sounds, tastes, lights, textures, colors. But the degree to which they 
exhibit their symptoms may vary in severity. Self-injurious behaviors (SIB) are not considered a core characteristic of the ASD population however approximately $50 \%$ of those with ASD take part in some type of SIB (head-banging, self-biting) and are more at risk than other groups with developmental disabilities (Minshawi, Hurwitz, Fodstad, Biebl, Morriss, \& McDougle, 2014). One of the theories that explain autism states that executive functions related to planning, working memory, impulse control, inhibition, and mental flexibility are typically impaired in people with neurodevelopmental disorders involving frontal lobe deficits.

\section{Executive Functioning skills}

Executive function (EF) refers to a set of cognitive abilities that allow individuals to control thoughts and actions in the face of new or complex situations in which an automatic or impulsive response is not useful (Miyake and Friedman, 2012). Executive function (EF) refers to a set of higher order cognitive processes that control and modulate cognition under continuously changing and multiple task demands (Traverso, Viterbori, \& Usai, 2015). Executive functions are defined as a set of general purpose mechanisms that regulate action and cognition. They are commonly composed of three related, albeit separate, components: shifting, which involves moving back and forth between multiple tasks, operations, or mental sets; updating, which requires monitoring and actively manipulating working memory representations; and inhibition, which is the ability to deliberately inhibit a dominant, automatic, or prepotent response (Miyake \& Friedman, 2012). According to this theory called as executive dysfunction theory, the difficulties in communication and social interaction and, mainly, the restricted patterns of interests and behavior could be explained by inadequate ability for planning, deficient working memory abilities, lack of control and impulse inhibition, and insufficient mental flexibility (Lopez, Lincoln, Ozonoff, \& Lai, 2005).

Basic cognitive processes such as attention control, cognitive inhibition, inhibitory control, working memory, cognitive flexibility planning, and problem solving are a part of executive functions skills. In autism, executive functions play a substantial role in autistic children's developmental outcomes including their social competence (which allow individuals to evaluate social situations and respond effectively), their adaptive behavior (those skills necessary for individuals to live independently and to function well in real-life settings), and their success in school (Pellicano, 2012). Higher order executive functions require the simultaneous use of multiple basic executive functions and include planning and fluid intelligence, such as reasoning and problem solving (Chan, Shum, Toulopoulou \& Chen, 2009; Diamond, 2013). Being able to inhibit impulses is one aspect of executive function, that allow us to manage complex or complicated information, solve more unexpected problems and fine-tune our behavior.

Executive function also includes the ability to plan, hold information in mind, and shift flexibly between different rules in different situations. Strengthening executive function can help children with autism spectrum disorder (ASD) function better in social situation. Studies suggest that more than half of children with ASD have impaired in executive control, even when their IQ is in the normal range or higher. Executive function helps a person to understand the perspective of other people, which is often challenging for children with autism. The element in executive functioning skills are attention, working memory, transitioning, emotional regulation, abstract planning, impulse control, flexibility, and problem solving skills 
(www.oregonbehavior.com/forms). According Diamond (2013), core executive functions are inhibition and interference control (selective attention and cognitive inhibition), working memory, and cognitive flexibility (including creatively thinking outside the box, seeing anything from different perspectives, and quickly and flexibly adapting to changed circumstances).

(a) Attention refers to an ability to stay focus on task. Attention control refers to an individual's capacity to choose what they pay attention to and what they ignore. But to autism, it is difficult to hold attention whether to learn new things or to complete a task given. They may pay little attention to an activity that does not fall into their particular area of interest. Attention problems may occur if the child does not understand what is being said due to his poor receptive language skills. Attention also involve selective attention which means a child must ignore distractions to keep paying attention.

(b) Working memory is an ability to learn information and use that information for the current activity. Working memory is a cognitive system with a limited capacity that is responsible for temporarily holding information available for processing. Working memory is important for reasoning and the guidance of decision-making and behavior (Diamond, 2013). Memory is the ability to recall knowledge that had already been understood. It is a strong ability to understand and does not necessarily equate to having a good memory.

(c) Transitioning refers to moving from one activity or environment to another (www.oregonbehavior.com/forms). Individuals with autism spectrum disorders (ASD) may have greater difficulty in shifting attention from one task to another or in changes of routine. This may be due to a greater need for predictability and challenges in understanding what activity will be coming next (Mesibov, Shea, \& Schopler, 2005), or difficulty when a pattern of behavior is disrupted.

(d) Emotional regulation is an ability to keep calm when getting frustrated, stressed, or overstimulated and keeping calm in the moment and remembering the plan (or "good choice") and following it (www.oregonbehavior.com/forms). Emotional self-regulation belongs to the broader set of emotion-regulation processes, which includes both the regulation of one's own feelings and the regulation of other people's feelings (Burman, Green, \& Shanker, 2015). Emotional regulation is a complex process that involves initiating, inhibiting, or modulating one's state or behavior in a given situation - for example the subjective experience (feelings), cognitive responses (thoughts), emotionrelated physiological responses (for example heart rate or hormonal activity), and emotion-related behavior (bodily actions or expressions). Functionally, emotional regulation can also refer to processes such as the tendency to focus one's attention to a task and the ability to suppress inappropriate behavior under instruction.

(e) Abstract planning and sequencing means creating a logical short term plan without writing it down and sticking to it. Whereas abstract planning and flexibility relates to being able to consider several solutions or plans, not only the first one that comes to mind. A child would also have thinking hypothetically in abstract planning (www.oregonbehavior.com/forms).

(f) Impulse control planning refers to thinking before doing and impulse control thinking is happen before responding to a question (www.oregonbehavior.com/forms). 
Vol. 8, No. 3, 2019, E-ISSN: 2226-6348 @ 2019 HRMARS

(g) cognitive flexibility means an ability handling unexpected changes in the plan or to the routine. Cognitive flexibility has been described as the mental ability to switch between thinking about two different concepts, and to think about multiple concepts simultaneously (www.oregonbehavior.com/forms). Two subcategories of cognitive flexibility are task switching and cognitive shifting, depending on whether the change happens unconsciously or consciously. Difficulties in cognitive flexibility in autism are related to deficits in the theory of mind, communication skills, and maladaptive behaviors (Memari, Ziaee, Shayestehfar, Ghanouni, \& Mansournia, 2013) which are associated with quality of life (Vries \& Geurts, 2015).

(h) problem-solving flexibility means being flexible about a change once it is explained and understood sequencing skills (www.oregonbehavior.com/forms). Problem-solving types and steps varied across studies, all required students to define a problem, generate, and implement solutions. Evidence indicated that students with ASD could learn to engage in problem solving independently following the intervention (Yakubova, \& Taber-Doughty, 2017).

Additionally, the ability to regulate and control actions and cognitions, such as executive functions, has been associated with school success, which has resulted in a strong effort to develop executive functions training programs to improve students' executive functions and academic achievement (Pellicano, 2012). Given the essential role of executive function in children's successful development, numerous training programs have been developed to improve children's executive functions skills.

\section{Cognitive Training in Autism}

Cognitive skills focus on how well the kid is reacting to your cues. Early studies on development in autism focused on basic capacities of perception and sensory abilities. When cognitive skills are reinforced, children with autism think, learn, and perform mentally at school, work, and life with greater ease. They need to go for the intervention as an alternative treatment to improve cognitive skills. The treatment options for autistic kids are interdisciplinary, which includes psychological treatment, speech-language therapy and occupational therapy. Research done by Vries et al (2015) proven that children with autism in all conditions who completed the training improved in working memory, cognitive flexibility, attention, but not in inhibition. For the study, children with autism were randomly assigned to an adaptive working memory (WM) training, an adaptive cognitive flexibility-training, or a non-adaptive control training (mocktraining). Braingame Brian, a computerized executive functions training with game-elements, was used. Outcome measures (pre-training, post-training, and 6-week-follow-up) were neartransfer to trained executive functions, far-transfer to other executive functions (sustained attention and inhibition), and parent's ratings of daily life executive functions, social behavior, attention deficit hyperactivity disorder (ADHD)-behavior, and quality of life. Whereas, Benyakorn et al (2018) indicated that children with autism spectrum disorder and intellectual impairments can successfully participate in computerized cognitive training interventions but may require additional weeks to complete the training beyond the time needed for children without intellectual impairments. 
In Malaysia, the MyNeuroLAT training program was introduced to children with autism recently. This training program trains the user to have the ability to answer the question correctly. Developing these cognitive abilities is not through being taught how to answer, but rather these abilities are developed through training and practice. However for cognitive ability training, it is only through practice that the trainee is able to improve. Therefore it is necessary to continuously practice on similar training sessions.

\section{Methodology}

This study examines specifically on the cognitive skills base on a program prepared by NeuroLAT Sdn Bhd. The NeuroLAT program does not train the user on academic subjects but on cognitive abilities. When the trainee is told the right answer and scores in the test, it does not mean that the trainee has successfully developed the necessary cognitive abilities. The trainee should know that getting the right answer is not the main focus of the MyNeuroLAT training program. The software is designed for participant to be completed individually with the use of computer. Participant were given approximately one to two hours to answer the question in the training session. Through the training session, data were computerize recorded and result were appeared in the graph. For children with mild autism, most of them could finished the exercises faster than the time given. A trainer must accompany a participant to help and guide the participant if needed.

For data collection, this case study used interviews, observations and document analysis. An interview session was conducted to obtain qualitative data. Interviews were conducted individually with teacher and trainer. Observation is carried out during intervention activities for about 40 minutes for each participants. Instruments used in collecting data were checklists, field notes, and training records. Two checklists were used in data collection (Executive functioning skills in training program 1 and Executive functioning skills in training program 2) which was adapted from www.oregonbehavior.com/forms (with permission). Documents referenced were training records. This case study was analyzed and reported descriptively and supported by reference statistics.

\section{Results}

The cognitive training program were used to improve skills in attention (EF1 \& EF2), working memory (EF3), transitioning (EF4), emotional regulation (EF5 \& EF6), selective attention (EF7), abstract planning (EF8, EF9 \& EF10), impulse control (EF11 \& EF12), flexibility (EF13), and problem solving skills (EF14). Table 1 and Table 2 has showed the findings of executive functioning skills score in the training program 1 and training program 2. Level of executive functioning skills were determined by level of score as AG (always good), SG (sometimes good), JD (just depends), SS (sometimes struggle), and AS (always struggle). 10 autism children were involved in this training. Training period is four months. Each participant were given the same task in the training. Result is shown in the Table 1 and Table 2. 
INTERNATIONAL JOURNAL OF ACADEMIC RESEARCH IN PROGRESSIVE EDUCATION AND DEVELOPMENT

Vol. 8, No. 3, 2019, E-ISSN: 2226-6348 @ 2019 HRMARS

Table 1. Executive functioning skills in Training Program 1

\begin{tabular}{|c|l|c|c|c|c|c|c|}
\hline \multirow{2}{*}{$\begin{array}{c}\text { No/ } \\
\text { Code }\end{array}$} & \multicolumn{1}{|c|}{ Executive Functioning Skills } & AG & SG & JD & SS & AS & Total \\
\hline EF1 & Attention : learn a new task & & 3 & 5 & 2 & & 10 \\
\hline EF2 & $\begin{array}{l}\text { Attention : complete an everyday } \\
\text { task }\end{array}$ & & 3 & 5 & 2 & & 10 \\
\hline EF3 & $\begin{array}{l}\text { Working Memory : learn and use } \\
\text { information for the current } \\
\text { activity }\end{array}$ & & 2 & 2 & 6 & & 10 \\
\hline EF4 & Transitioning & & & & & \\
\hline EF5 & $\begin{array}{l}\text { Emotional Regulation : Keeping } \\
\text { calm }\end{array}$ & & 2 & 5 & 1 & 2 & 10 \\
\hline EF6 & $\begin{array}{l}\text { Emotional Regulation : Keeping } \\
\text { calm in the moment and } \\
\text { remembering the plan }\end{array}$ & & 2 & 3 & 3 & 2 & 10 \\
\hline EF7 & Selective Attention & & & & & & \\
\hline EF8 & Abstract Planning and Sequencing & & 2 & 4 & 2 & 2 & 10 \\
\hline EF9 & Abstract planning, Flexibility & & 2 & 1 & 6 & 1 & 10 \\
\hline EF10 & $\begin{array}{l}\text { Abstract planning / thinking } \\
\text { hypothetically }\end{array}$ & & 2 & & 5 & 1 & 8 \\
\hline EF11 & Impulse Control, planning & & 3 & 1 & 5 & 1 & 10 \\
\hline EF12 & Impulse Control Thinking & & 2 & 1 & 5 & 2 & 10 \\
\hline EF13 & Flexibility & & 1 & 3 & 6 & & 10 \\
\hline EF14 & Problem-Solving, Flexibility & & 2 & 1 & 6 & 1 & 10 \\
\hline & Total & & & & & & \\
\hline & $\%$ & 29 & 41 & 53 & 14 & 138 \\
\hline
\end{tabular}

Table 1 shows the score in the executive functions in Training Program 1 which determined by AG (always good), SG (sometimes good), JD (just depends), SS (sometimes struggle), and AS ( always struggle). The most higher score in executive functions was SS with $38.41 \%$ which means participant showed $3.8 \mathrm{~min}$ score in the executive functions during training 1 . It was followed by JD with $29.71 \%$, SG $21.01 \%$, AS $10.14 \%$, and the lowest score was AG with $0.72 \%$. Findings showed that in training 1, participants sometimes struggle (SS) in doing task. Only one participant has shown always good (AG) in completing task for EF4 (transitioning). In addition, 6 participants were identified sometimes struggle in EF3 (working memory), EF9 (abstract planning), EF13 (flexibility), and EF14 (problem solving). It is clearly shown that the total $38.41 \%$ children with autism are sometimes struggle in executive functions during Training Program 1 for a period of four months. Only one participant shows always good (AG) in transitioning (EF4) which means he/she is good in moving or going from one activity to another activity in the training program 1. The exercise in the training program were designed according to the learning on concepts such as numbers, forms, sizes, colors and symbols. 
Vol. 8, No. 3, 2019, E-ISSN: 2226-6348 @ 2019 HRMARS

For the purpose of improving skills in executive functions using cognitive training program, Table 2 has showed the progress in executive functions in Training Program 2. Participants were continued the training session for another four months. At this level, participant also given a task in the software to be completed. The exercise in the Training Program 2 were more challenging and participants needs to answer question in the software depends on the time given. In Training Program 2, participants already learned the pattern and had experience in answering the question. It could be easier for them to understand and follow instruction in completing the exercise.

Table 2. Executive functioning skills in Training Program 2

\begin{tabular}{|c|l|c|c|c|c|c|c|}
\hline \multirow{2}{*}{$\begin{array}{c}\text { No/ } \\
\text { Code }\end{array}$} & \multicolumn{1}{|c|}{ Executive Functioning Skills } & \multicolumn{5}{|c|}{ Level } \\
\cline { 2 - 7 } & & AG & SG & JD & SS & AS & Total \\
\hline EF1 & Attention : learn a new task & 1 & 2 & 6 & 1 & 10 \\
\hline EF2 & $\begin{array}{l}\text { Attention : complete an } \\
\text { everyday task }\end{array}$ & 1 & 2 & 6 & 1 & 10 \\
& $\begin{array}{l}\text { Working Memory : learn and use } \\
\text { information for the current } \\
\text { activity }\end{array}$ & 1 & 2 & 6 & 1 & & 10 \\
\hline EF4 & Transitioning & & & & & \\
\hline EF5 & $\begin{array}{l}\text { Emotional Regulation : Keeping } \\
\text { calm }\end{array}$ & 1 & 2 & 4 & 3 & & 10 \\
\hline EF6 & $\begin{array}{l}\text { Emotional Regulation : Keeping } \\
\text { calm in the moment and } \\
\text { remembering the plan }\end{array}$ & 1 & 2 & 4 & 3 & & 10 \\
\hline EF7 & Selective Attention & 1 & 2 & 3 & 4 & & 10 \\
\hline EF8 & $\begin{array}{l}\text { Abstract Planning and } \\
\text { Sequencing }\end{array}$ & 1 & 2 & 2 & 5 & & 10 \\
\hline EF9 & Abstract planning, Flexibility & 1 & 2 & 3 & 4 & & 10 \\
\hline EF10 & $\begin{array}{l}\text { Abstract planning / thinking } \\
\text { hypothetically }\end{array}$ & 1 & 2 & 2 & 5 & & 10 \\
\hline EF11 & Impulse Control, planning & 1 & 2 & 2 & 5 & & 10 \\
\hline EF12 & Impulse Control Thinking & 1 & 2 & 4 & 3 & 10 \\
\hline EF13 & Flexibility & 1 & 2 & 4 & 3 & & 10 \\
\hline EF14 & Problem-Solving, Flexibility & 1 & 2 & 4 & 3 & & 10 \\
\hline & Total & 14 & 28 & 56 & 42 & 140 \\
\hline & $\%$ & 10.00 & 20.00 & 40.00 & 30.00 & 100 \\
\hline
\end{tabular}

Table 2 showed the result of Training Program 2 which was clearly shown that the executive functions was improve drastically. Obviously, the level were increased in always good (AG) and AS (always struggle) which means in level AG, number of score were increased from 1 to 14, whereas in level AS, the number of score were decreased from 14 to 0 . For overall score in the executive functions were analyzed as JD (it just depends) with $40.00 \%$, SS (sometime struggle) 
$30.00 \%$, SG (sometimes good) $20.00 \%$, and AG (always good) $10.00 \%$. The most highest score in the training can be seen in level it just depends (JD) which refers to EF1 (attention), EF2 (attention), EF3 (working memory), and EF4 (transitioning). Working memory (EF3) remain same to be the toughness task to be completed.

\section{Discussion}

The present study was conducted to examine the effectiveness of an executive function training program that was developed to be suitable for educational services using software resources. The training targets four to 12 year-old children from the National Autistic Society of Malaysia (NASOM). The training uses a series of cognitive training software which was designed to improve cognitive skills among autistic children. One aspect of cognitive skills were executive functions. The development of an executive function intervention that can be easily implemented in educational services could be useful for enhancing school readiness and reducing the gap in executive function development between typical and special needs children (such as children from disadvantaged contexts and those with poor working memory or suspected autism), especially when they are not yet properly identified (Traverso, Viterbori, and Usai, 2015; Madrid, Ahmed, \& Kumar, 2019).

In executive functions, the skills in attention, working memory, transitioning, abstract planning, flexibility, and problem solving were among the skills in the executive functions that are most struggled by children with autism. Attention are much challenging skill to autism because most autism are hardly to hold attention whether to learn new things or to complete a task given. They may pay little attention to an activity that does not fall into their particular area of interest. Autism also struggling with working memory skills which means they had problem in learning new information and use that information for the current activity. They can't temporarily holding information available for processing information. As mentioned by Diamond (2013), working memory is important for reasoning and the guidance of decision-making and behavior. This skills need to be practiced and used regularly.

Most autism face problem in transitioning skill, which refers to moving from one activity or environment to another. It is proven that autism is having problem with changing situation or moving from activity to another. They have difficulties in performing daily tasks, creating and keeping relationships, and maintaining a task (Comer, 2016). It is difficult for them to change focus in very short time. Some individuals with ASD may have difficulties associated with changes in routine or changes in environments, and may have a need for "sameness" and predictability Mesibov, Shea, \& Schopler, (2005); Khalid, Pahi, \& Ahmed, (2016). Besides that, study also confirmed that autism have difficulties in abstract planning and sequencing which means they are hardly creating a logical short term plan without writing it down and sticking to it. Problem also encountered in abstract planning and flexibility which relates to being able to consider several solutions or plans, not only the first one that comes to mind. Problem solving also proven as one of the difficulties in executive functions for children with autism. Problem-solving flexibility means being flexible about a change once it is explained and understood sequencing skills. It is very challenging for autism to solve problem in daily life. Individuals with ASD exhibit challenges in connecting past experiences with present and future actions, they frequently 
Vol. 8, No. 3, 2019, E-ISSN: 2226-6348 @ 2019 HRMARS

struggle with problem solving (Tsatsanis, 2005). But students with ASD could learn to engage in problem solving independently following the intervention (Yakubova, \& Taber-Doughty, 2017).

\section{Conclusion}

The number of times and regularity of the trainee's training directly affects the progress in executive functions skill. The regularity of a trainee's training would affect the progress of their cognitive ability to a large extent. For example, training 3 times on one day, and then training only once after taking a break for a week sometimes will affect their result. This is not good at all for the training of cognitive abilities. Whatever training is conducted, time play an important factor to be considered. For cognitive training in NASOM, participants were given specific time to complete the exercise. As mention by Benyakorn et al (2018) require additional weeks to complete the training beyond the time needed for children without intellectual impairments. Children with autism needs some extra time to do the exercise because their ability to learn and stay focus is quite different with typical child. Actually, regardless of whatever the training is for, as long as training is done with regularity, the end result of the training would be better.

The trainee's various cognitive abilities are of varying levels so it is normal for them to achieve different result. The trainee's pace of learning may be fast or slow, so the result also will be different. There are two reasons for fast progress. Firstly, the trainee fulfill this ability naturally, so the progress of learning is quite fast and this ability will improve after systematic training. Secondly, it may be because the trainee had sufficient prior training in this ability, and have already reached the level he is personally capable of skill. Hence there will be many obvious improvements despite the systematic training. Every learning ability can be trained, and can be improved on. There is no need to think that this is the final result or worry that this is a fact that can never be changed. On the contrary, this is the beginning of change, and it is entirely possible to have further improvement.

\section{Acknowledgement}

The authors would like to express their highest gratitude to MyNeuroLAT Sdn Bhd for the funding of this research project via code number 201 8-0094-1 06-29.

\section{Corresponding Author}

Norfishah Mat Rabi, Faculty of Human Development, Universiti Pendidikan Sultan Idris, Malaysia.

Email: norfishah@fpm.upsi.edu.my

\section{References}

Khalid, N., Pahi, M. H., \& Ahmed, U. (2016). Loosing your best talent: Can leadership retain employees? The dilemma of the banking sector of Hyderabad Sindh, Pakistan: A mediation investigation. International Review of Management and Marketing, 6(3), 608616.

Madrid, D., Ahmed, U., \& Kumar, R. (2019). Examining the Impact of Classroom Environment on Entrepreneurship Education: Case of a Private University in Bahrain. Journal of Entrepreneurship Education, 22(1), 1-8. 
INTERNATIONAL JOURNAL OF ACADEMIC RESEARCH IN PROGRESSIVE EDUCATION AND DEVELOPMENT

Vol. 8, No. 3, 2019, E-ISSN: 2226-6348 @ 2019 HRMARS

Accordino, R. E., Kidd, C., Politte, L. C., Henry, C. A., \& McDougle, C. J. (2016). "Psychopharmacological interventions in autism spectrum disorder". Expert Opinion on Pharmacotherapy. 17 (7): 937-52. doi:10.1517/14656566.2016.1154536.

American Psychiatric Association. (2013). Autism Spectrum Disorder. 299.00 (F84.0). Diagnostic and Statistical Manual of Mental Disorders, Fifth Edition (DSM-5). Arlington, VA: American Psychiatric Publishing.

Burman, J. T., Green, C. D. \& Shanker, S. (2015). On the Meanings of Self-Regulation: Digital Humanities in Service of Conceptual Clarity. Child Development. 86 (5): 1507-1521. doi:10.1111/cdev.12395

Chan, R. C., Shum, D., Toulopoulou, T., \& Chen, E. Y. (2008). Assessment of executive functions: review of instruments and identification of critical issues. Archives of Clinical Neuropsychology. 23 (2): 201-216. doi:10.1016/j.acn.2007.08.010. PMID 18096360

Comer, R. J. (2016). Fundamentals of Abnormal Psychology. New York: Worth /Macmillan Learning.

Diamond, A. (2013). Executive functions. Annual Review of Psychology. 64: 135-168. doi:10.1146/annurev-psych-113011-143750.

Freitag, C. M. (2007). The genetics of autistic disorders and its clinical relevance: a review of the literature. Molecular Psychiatry. 12 (1): 2-22. doi:10.1038/sj.mp.4001896

Hill, E. L. (2004). Executive dysfunction in autism. Trends in Cognitive Science, 8(1), 26-32. doi:https://doi.org/10.1016/j.tics.2003.11.003

Kulage, K. M., Smaldone, A. M., Cohn, E. G. (August 2014). How will DSM-5 affect autism diagnosis? A systematic literature review and meta-analysis. Journal of Autism and Developmental Disorders. 44 (8): 1918-32. doi:10.1007/s10803-014-2065-2.

Lopez, B. R., Lincoln, A. J., Ozonoff, S., \& Lai, Z. (2005). Examining the relationship between executive functions and restricted, repetitive symptoms of autistic disorder. Journal of Autism and Developmental Disorders, 35(4), 445-460. doi:https://doi.org/10.1007/s10803-005-5035-x

Memari, A. H., Ziaee, V., Shayestehfar, M., Ghanouni, P., Mansournia, M. A., \& Moshayedi, P. (2013). Cognitive flexibility impairments in children with autism spectrum disorders: links to age, gender and child outcomes. Research in Developmental Disabilities, 34, 3218-3225. doi:https://doi.org/10.1016/j.ridd.2013.06.033

Mesibov, G., Shea, V., \& Schopler, E. (2005). The TEACCH ${ }^{\circledR}$ approach to autism spectrum disorders. New York, NY: Plenum Publishers.

Minshawi, N. F., Hurwitz, S., Fodstad, J. C., Biebl, S., Morriss, D. H., \& McDougle, C. J. (2014). The association between self-injurious behaviors and autism spectrum disorders. Psychology Research and Behavior Management. 7: 125-36. doi:10.2147/PRBM.S44635.

Miyake, A., \& Friedman, N. P. (2012). The Nature and Organization of Individual Differences in Executive Functions: Four General Conclusions. Curr Dir Psychol Sci. 2012 Feb; 21(1):8-14.

Pellicano, E. (2012). The development of executive function in autism. Autism Res. Treat. 2012:146132. 10.1155/2012/146132

Richler, J., Huerta, M., Bishop, S.L., \& Lord, C. (2010). Developmental trajectories of restricted and repetitive behaviors and interests in children with autism spectrum disorders". Development and Psychopathology. 22 (1): 55-69. doi:10.1017/S0954579409990265. 
Traverso, L., Viterbori, P., \& Usai, M. C. (2015). Improving executive function in childhood: evaluation of a training intervention for 5-year-old children. Front Psychol. 2015; 6: 525. doi: 10.3389/fpsyg.2015.00525.

Tsatsanis, K. (2005). Neuropsychological characteristics of autism and related conditions. In F. R. Volkmar, R. Paul, A. Klin, \& D. Cohen (Eds.), Handbook of autism and developmental disorders (pp. 365-381). Hoboken, NJ: Wiley.

Vries, M. D., \& Geurts, H. (2015). Influence of autism traits and executive functioning on quality of life in children with an autism spectrum disorder. Journal of Autism Developmental Disorder, 45(9), 2734-2743. doi:https://doi.org/10.1007/s10803-015-2438-1.

Vries M. D., Prins, P. J., Schmand, B. A., \& Geurts, H. M. (2015). Working memory and cognitive flexibility-training for children with an autism spectrum disorder: a randomized controlled trial. J Child Psychol Psychiatry. 2015 May;56(5):566-76. doi: 10.1111/jcpp.12324.

Yakubova, G. \& Taber-Doughty, T. (2017). Improving Problem-Solving Performance of Students With Autism Spectrum Disorders. Focus on Autism and Other Developmental Disabilities, Vol. 32(1) 3-17. 